\title{
Correction to: D-Pinitol: a cyclitol with versatile biological and pharmacological activities
}

\author{
Marina Sánchez-Hidalgo (i) - Antonio J. León-González $\mathbb{D}$ • \\ Marina Gálvez-Peralta (1) - Nuria H. González-Mauraza • \\ Carmen Martin-Cordero
}

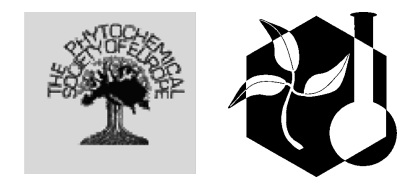

Published online: 30 January 2021

(C) Springer Nature B.V. 2021

\section{Correction to: Phytochem Rev}

https://doi.org/10.1007/s11101-020-09677-6

In the original publication, the Figures 1, 2 and 4 were published incorrectly. The correct figures are updated in this correction.

The original article can be found online at https:// doi.org/10.1007/s11101-020-09677-6.

M. Sánchez-Hidalgo · N. H. González-Mauraza ·

C. Martin-Cordero ( $\square)$

Department of Pharmacology, School of Pharmacy, University of Seville, Seville, Spain

e-mail: carmenmc@us.es

\section{A. J. León-González}

Maimonides Institute for Biomedical Research of

Cordoba (IMIBIC), Córdoba, Spain

M. Gálvez-Peralta

Department of Pharmaceutical Sciences, West Virginia

University School of Pharmacy, Morgantown 26506, USA 
Fig. 1 Chemical structure of D-pinitol<smiles>CO[C@H]1[C@@H](O)[C@H](O)[C@@H](O)[C@H](O)[C@H]1O</smiles>

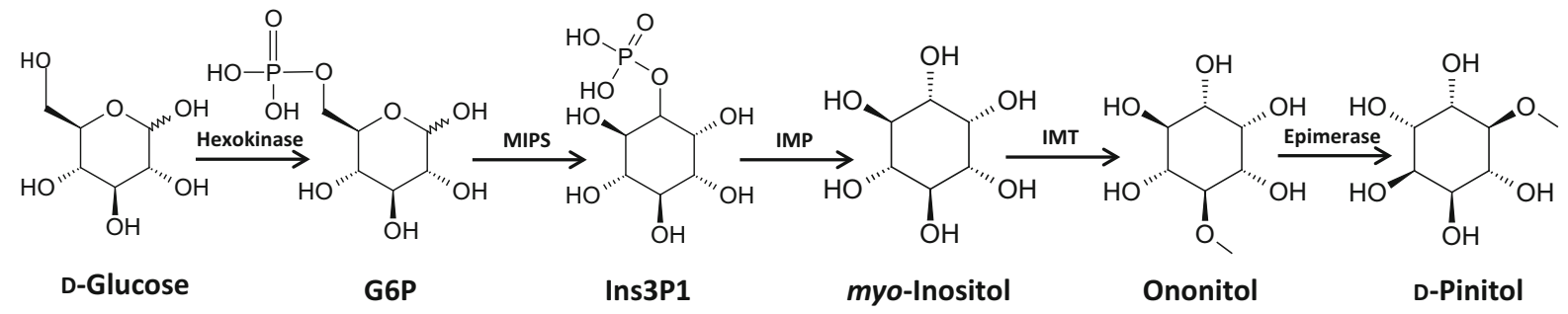

Fig. 2 Biosynthesis of D-pinitol in plants through Loewus pathway. G6P, D-glucose-6-phosphate; IMP, inositol monophosphatase; IMT, inositol methyltransferase; Ins3P1, 1-1-myo-inositol-1-phosphate; MIPS, myo-inositol-1-1-phosphate synthase

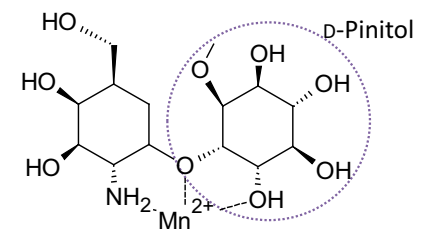

Fig. 4 Structure of insulin second messenger (INS-2). INS-2 is as a complex of D-pinitol and galactosamine, chelated to manganese
Publisher's Note Springer Nature remains neutral with regard to jurisdictional claims in published maps and institutional affiliations. 